\title{
CHANGES IN EXPRESSION OF NEUROPEPTIDES AND THEIR RECEPTORS IN THE HYPOTHALAMUS AND GASTROINTESTINAL TRACT OF CALORIE RESTRICTED HENS
}

\author{
ÁdÁm Simon, ${ }^{1}$ JÁnos OlÁH, ${ }^{1}$ IstVÁn Komlósi, ${ }^{1}$ ANdrÁs JÁVor, ${ }^{1}$ \\ JózSEF NÉMETh, ${ }^{2}$ ZOLTÁn SZILVÁSSY, ${ }^{2}$ DóRa ReglöDI, ${ }^{3}$ \\ ANDREa TAMÁs ${ }^{3}$ and LeVENTE CZEGLÉDI ${ }^{1 *}$ \\ ${ }^{1}$ Department of Animal Science, Faculty of Agricultural and Food Sciences and Environmental \\ Management, University of Debrecen, H-4027 Debrecen, Böszörményi út 138, Hungary \\ 2Department of Pharmacology and Pharmacotherapy, Faculty of Medicine, University of Debrecen, \\ H-4032 Debrecen, Nagyerdei körút 98, Hungary \\ ${ }^{3}$ Department of Anatomy, University of Pécs Medical School, H-7624 Pécs, Szigeti út 12, Hungary
}

(Received: November 17, 2016; accepted: April 11, 2017)

\begin{abstract}
The list of orexigenic and anorexigenic peptides, those are known to alter feed intake, is continuously growing. However, most of them are studied in mammalian species. We aimed to investigate plasma level and mRNA expression of the pituitary adenylate cyclase-activating polypeptide (PACAP), gene expression of its receptor (PAC1), furthermore the gene expression of galanin (GAL), neuromedin $U$ (NMU), and its two receptors (NMUR1 and NMUR2) in the hypothalamus, proventriculus, and jejunum of hens exposed to $40 \%$ calorie restriction. Feed restriction resulted in a $88 \%$ increase in mRNA and a $27 \%$ increase in peptide level of PACAP in proventriculus measured with qPCR and RIA, respectively. Increases were found in the gene expression of PAC1 $(49 \%)$ and NMUR1 $(63 \%)$ in the hypothalamus. Higher expressions of peptide encoding genes ( $76 \%$ for PACAP, $41 \%$ for NMU, $301 \%$ for NMUR 1 and $308 \%$ for GAL, $P<0.05$ ) were recorded in the jejunum of hens exposed to restricted nutrition. The results indicate that PACAP level responds to calorie restriction in the proventriculus and jejunum, but not in the hypothalamus and plasma.
\end{abstract}

Keywords: Calorie restriction - GAL - NMU - PAC1 - PACAP

\section{INTRODUCTION}

Complex mechanisms regulate feed intake in vertebrates. Feed intake regulation involves sites both in the central nervous system and in the peripheral organs, and signals are integrated within the hypothalamus. In regard of feed intake regulation and energy homeostasis, several peptides have been intensively studied [5, 12, 41], but there are considerably less peptides known in chickens with potential function of modifying feed intake.

Pituitary adenylate cyclase-activating polypeptide (PACAP) in chicken differs in only one isoleucine compared to the cattle, human, pig, rat or sheep counterparts [44]. Chicken PAC1 receptor is widely expressed in a variety of central and peripheral tis-

\footnotetext{
*Corresponding author; e-mail address: czegledi@agr.unideb.hu
} 
sues including brain, testis, ovary, kidney, small intestine, lung, and heart [34]. PACAP can be found in tissues like brain [19], pancreas [15], small intestine [33], but it has not yet been described in the blood of avian species, in contrast to mammals [7]. PACAP is truly a multifunctional peptide having a complex role in the regulation of physiological processes in chicken, like feed intake [20], chondro- and osteogenesis [21], and antiapoptotic effect in oxidative stress [37]. PAC1 can be found in the chicken infundibular nucleus of hypothalamus [35], which is the main site of food intake regulation containing orexigenic and anorexigenic neuronal projections.

Neuromedin U (NMU) peptide consists of 25 amino acids. NMU was first isolated from the small intestine of the chicken and the sequenced peptide showed that its C-terminal 18-25 displays 100\% similarity with other vertebrae species like rat, frog, guinea pig, rabbit, counterparts, while it only differs in one amino acid from porcine NMU [11]. This C-terminal evolutionary conserved sequence is responsible for the biological activities of NMU. Despite the fact that NMU was isolated from chickens more than 20 years ago, it is still a moderately studied peptide in avian species. NMU acts on its G-protein coupled, 7TM receptors, namely NMUR1 and NMUR2 [17]. Tissue distribution of the two receptors showed that NMUR1 is mainly expressed in the gastrointestinal tract, but NMUR2 is expressed only in specific brain regions. NMU receptor distribution suggests that NMU can be involved in both intestinal and central actions [43].

Galanin (GAL), a 29 amino acid peptide. It is co-expressed with neuropeptide Y, vasoactive intestinal peptide (VIP) and substance $\mathrm{P}$ in the chicken respiratory tract, mainly in the epithelial and subepithelial layers of trachea [28] and it can also be found in medullary cells [46]. Furthermore, it is expressed in the nucleus supraopticus of chicken hypothalamus and it shows sexual dimorphism indicating that galanin may be involved in the regulation of oviposition [24].

In addition to the most studied central neuropeptides involved in chicken feed intake regulation, such as agouti-related protein (AGRP) [41], neuropeptide Y (NPY) [12], cocaine and amphetamine regulated transcript (CART) [5], possibly a number of other neuropeptides may participate in this process. In the present study, we aimed to investigate how gene expression of less studied peptides (PACAP, neuromedin U, galanin) and their receptors occurring in the hypothalamus and gastrointestinal system respond to long-term calorie restriction at mRNA and protein levels. We supposed that $P A C A P$ and $N M U$ expression down-regulation and $G A L$ up-regulation would be involved in responding to feed restriction.

\section{MATERIALS AND METHODS}

\section{Birds}

In order to avoid potential gender specific different responses to the calorie restriction we used 16 female, 22 weeks old layer type chickens (Tetra-SL line). Birds were individually housed to ground pens. During the one week long adaptation period, 
both groups were fed on ad libitum layer 1 diet (briefly: $17.5 \%$ crude protein with a metabolizable energy of $11.7 \mathrm{MJ} / \mathrm{kg}$ dry matter, $3.8 \% \mathrm{Ca}, 0.4 \% \mathrm{P}$ ). Lighting regime and nutritional composition of the diet were implemented in accordance with the Tetra-SL management manual. After the adaptation period, half of the birds were maintained on $40 \%$ feed restricted diet (restricted group, 8 chickens) for 5 days, whereas the other group was fed ad libitum (control group, 8 chickens). Water was freely available in each pen during the whole experiment. After 5 days, each bird was sacrified by concussion. The experiment was approved by the University of Debrecen Committee of Animal Welfare, Hungary (permit number: DEMAB/12-7/2015).

\section{Isolation of hypothalamus, proventriculus, jejunum and plasma samples}

Whole hypothalamus was macrodissected according to the chicken brain atlas [25]. Each dissection was carried out within $15 \mathrm{~min}$. After opening the abdominal cavity, the proventriculus and jejunum samples were immediately removed, opened along the longitudinal axis and washed in ice-cold distilled water. Dissected tissues were immediately frozen in liquid nitrogen and stored at $-80^{\circ} \mathrm{C}$. Five $\mathrm{mL}$ blood from each bird was collected in EDTA coated blood collection tubes (S-Monovette ${ }^{\circledR}$, Sarstedt, Germany) and it was centrifuged at $2000 \times g$ for 10 minutes. Aliquots of plasma samples were immediately frozen in liquid nitrogen and stored at $-80{ }^{\circ} \mathrm{C}$ for further analysis.

\section{$R N A$ isolation, reverse transcription and quantitative real-time PCR (qPCR) assays}

Whole hypothalamus samples were grounded in liquid nitrogen with a mortar and pestle. RNA was extracted from $30 \pm 3 \mathrm{mg}$ grinded tissue using RNeasy ${ }^{\circledR}$ Mini Kit (Qiagen) with an on-column DNase I digestion step. Quantity and purity of isolated RNA were quantified using a NanoDrop ND-1000 ${ }^{\circledR}$ spectrophotometer (Thermo Fisher Scientific). Two $\mu \mathrm{g}$ RNA was reverse transcribed using a Maxima First Strand cDNA Synthesis Kit (Thermo Fisher Scientific), with reaction conditions as recommended in the kit's manual. After reverse transcription, aliquots were stored in $-20{ }^{\circ} \mathrm{C}$. Prior to qPCR, cDNA samples were diluted tenfold. cDNA specific primers were designed using Primer Express ${ }^{\circledR}$ v3.0.1. Real-time PCR reactions were run in triplicates (both reference and target genes on the same plate) on 96 reaction plates in an ABI 7300 real-time PCR machine (Life Technologies). Thermal profile was: $50^{\circ} \mathrm{C}$ for $2 \mathrm{~min}, 95^{\circ} \mathrm{C}$ for $10 \mathrm{~min}, 40 \mathrm{cycles}$ of $95^{\circ} \mathrm{C}$ for $15 \mathrm{sec}$ and $60^{\circ} \mathrm{C}$ for $30 \mathrm{sec}$. Realtime PCR reactions $(20 \mu \mathrm{l})$ contained $50 \mathrm{ng}$ of cDNA template, $1 \mathrm{X}$ Power $\mathrm{SYBR}^{\circledR}$ Green Master Mix (Life Technologies), and $200 \mathrm{nM}$ of each primer (Sigma-Aldrich). No template controls were included in each assay. Forward (F) and reverse (R) 5'-3' sequences of the primers for the selected genes with accession number in parentheses 
and the amplicon sizes (bp) were as follows: PAC1 (NM_001098606.1) CCAGTCACCTGATATTGGAGGC and AGTCTCTCCCGCTTACTGACA, (141); PACAP (NM_001001291.2) TAGACGGCATCTTCACGGACA and GCTACTCGGCGTCCTTTTGT,(124); GAL(NM 001159678.1)TAATCCTTTGTGCCGCCCTG and TCAATACGACGTGGCCCAAG, (112); NMU (NM_001277921.1) and CTTCTCTTCCTCCTCGCCTC and GTTCCTGCTCTGCCTCCAAC, (82); NMUR1 (XM_004943371.1) ACAGCGACTATCACAGAGTCCG and GCCCAGCAGATCCCAAACAC, (100); NMUR2 (XM_425209.4) AGTGTGCTGTACTATCTGATGGG and GCCTCTGAACATTCACGGACA, (85); ACTB (NM_205518.1) GGCTCCCCTGAACCCCAAA and ACCAGAGGCATACAGGGAC, (118); YWHAZ (NM_001031343.1) AGTCATACAAAGACAGCACGCTA and GCTTCATCTCCTTGGGTATCCGA, (85); Primer specificities were tested using melt curve analysis after each run. The most stable reference genes were selected from four candidates (ACTB, LBR, PGK1, YWHAZ) with NormFinder Excel add-in [1]. ACTB had the lowest NormFinder value proved to be the most stable reference gene in hypothalamus, whereas $Y W H A Z$ was the most stable in the proventriculus and jejunum as well. For the relative quantification, raw $\mathrm{Cq}$ values were normalized using the stable reference gene with the $\Delta \Delta \mathrm{Ct}$ method.

\section{Protein and plasma sample preparation and PACAP-38 radioimmunoassays}

Tissue samples of $75 \pm 0.5 \mathrm{mg}$ from hypothalamus, jejunum, and proventriculus were homogenized in $1.5 \mathrm{ml}$ ice cold distilled water with a rotor-stator homogenizer (UltraTurrax $^{\circledR}$ T10 IKA, Germany) for $30 \mathrm{sec}$. Homogenates were then centrifuged for 10 min at $20,000 \times g, 4{ }^{\circ} \mathrm{C}$. Supernatants were stored at $-80{ }^{\circ} \mathrm{C}$ for further analysis. The PACAP-38 peptide was extracted from $2 \mathrm{ml}$ plasma by addition of a double volume of absolute alcohol and $20 \mu 196 \%$ acetic acid. After precipitation and centrifugation $\left(1500 \times \mathrm{g}, 10 \mathrm{~min}, 4^{\circ} \mathrm{C}\right)$ the supernatants were decanted and dried under nitrogen flow. PACAP-38 immunoreactivity in chicken plasma and tissues was determined with a specific and sensitive RIA technique as previously described [18].

\section{Behavioral monitoring}

Each pen was observed by three investigators in the morning for one hour (between 8:00 and 9:00 AM on days 3, 4 and 5 of experiment) for behavioral pattern related to feed and water uptake (eating, drinking, scratching, pecking floor, seeking with stretched neck), physical activity (resting, walking) or related to comfort or stress behaviour (pecking tail feathers, pecking grid, wing stretching and feathering). Distinct behavioral pattern was counted as one, regardless of its duration. 


\section{Statistical analysis}

Statistical analysis was performed with GraphPad Prism ${ }^{\circledR} 6$ (La Jolla, California, USA) software for Windows using two-sided, unpaired $t$-test. qPCR Cq values were normalized with stable reference genes $\mathrm{Cq}$ vales. Result with $P<0.05$ was considered as statistically significant. All data were expressed as means \pm SEM.

\section{RESULTS}

There was no significant difference between the two groups $(P=0.542)$ in regard of mean liveweight $(g \pm$ SEM) before the experiment, values were $1814 \pm 53.32$ and $1769 \pm 48.35$ in the control and restricted groups, respectively. Feed intake ( \pm SEM) was recorded daily for each bird (it was 109.50土7.03 in the control group and $64.48 \pm 5.99$ in the ad libitum fed group).

RNA integrity checking with agarose gel electrophoresis showed no significant degradation. The annealing temperature at $60{ }^{\circ} \mathrm{C}$ resulted a single strong band for each amplicon confirmed by melt curve analysis, without detectable primer dimers or signs of non-specific amplification. No template controls were included in each assay and did not show any $\mathrm{Cq}$ value throughout the study. According to the $\mathrm{Cq}$ values all but one gene showed moderate expression in the examined tissues with mean $\mathrm{Cq}$ values above 15. PACAP showed the highest expression in the hypothalamus with mean $\mathrm{Cq}$ of 13.8 indicating an important role in the central nervous system.

Food restriction led to a $49 \%$ increase in the gene expression of PAC 1 receptor and a $63 \%$ increase in that of NMUR $1(P<0.05)$ measured by qPCR in the hypothalamus compared to ad libitum fed group (Table 1), but no significant effects were observed in the gene expression of PACAP, NMU, NMUR2 and GAL $(P>0.05)$. In the glandular stomach, food restriction significantly increased $(88 \%, P<0.05)$ the gene expression of PACAP compared to ad libitum fed group. No significant effects were found in the gene expression of PAC1, NMU, NMUR1, NMUR2 and GAL $(P>0.05)$.

Table 1

Effect of feed restriction on the expression of the selected genes (fold change \pm SEM)

\begin{tabular}{|l|c|c|c|c|c|c|}
\hline \multirow{2}{*}{ Gene } & \multicolumn{2}{|c|}{ Hypothalamus } & \multicolumn{2}{c|}{ Proventriculus } & \multicolumn{2}{c|}{ Jejunum } \\
\cline { 2 - 7 } & Control & Restricted & Control & Restricted & Control & Restricted \\
\hline$G A L$ & $1 \pm 0.05$ & $1.3 \pm 0.14$ & $1 \pm 0.11$ & $1.52 \pm 0.32$ & $1 \pm 0.02$ & $3.08^{*} \pm 0.02$ \\
\hline NMU & $1 \pm 0.04$ & $1.39 \pm 0.02$ & $1 \pm 0.06$ & $0.69 \pm 0.07$ & $1 \pm 0.02$ & $3.41^{*} \pm 0.19$ \\
\hline NMUR1 & $1 \pm 0.02$ & $1.63^{*} \pm 0.04$ & $1 \pm 0.07$ & $0.90 \pm 0.20$ & $1 \pm 0.05$ & $3.01 * \pm 0.09$ \\
\hline NMUR2 & $1 \pm 0.02$ & $1.5 \pm 0.10$ & $1 \pm 0.01$ & $1.04 \pm 0.06$ & $1 \pm 0.02$ & $0.52 \pm 0.01$ \\
\hline PAC1 & $1 \pm 0.02$ & $1.49^{*} \pm 0.03$ & $1 \pm 0.03$ & $1.07 \pm 0.12$ & $1 \pm 0.13$ & $1.01 \pm 0.02$ \\
\hline PACAP & $1 \pm 0.06$ & $1.26 \pm 0.10$ & $1 \pm 0.05$ & $1.88^{*} \pm 0.09$ & $1 \pm 0.03$ & $2.76^{*} \pm 0.08$ \\
\hline
\end{tabular}

$* P<0.05$ vs. control group. 
Highest gene expression changes were detected in the jejunum for PACAP, NMU, NMUR 1 and GAL with $276 \%, 341 \%, 301 \%$ and $308 \%(P<0.05)$ upregulation in the $40 \%$ feed restricted group, respectively. We could not detect any significant changes in the expression of PAC1 or NMUR2 genes $(P>0.05)$.

PACAP-38 was present in a detectable concentration in all of the investigated tissues, measured by RIA. Feed restriction increased PACAP peptide level with $21 \%$ $(P<0.05)$ only in the proventriculus (Fig. 1), and showed no significant changes in the hypothalamic and jejunal tissues and in the plasma $(P>0.05)$. PACAP-38 concentration of chicken plasma, measured in our experiment with RIA, was $\sim 20 \mathrm{fmol} / \mathrm{ml}$,

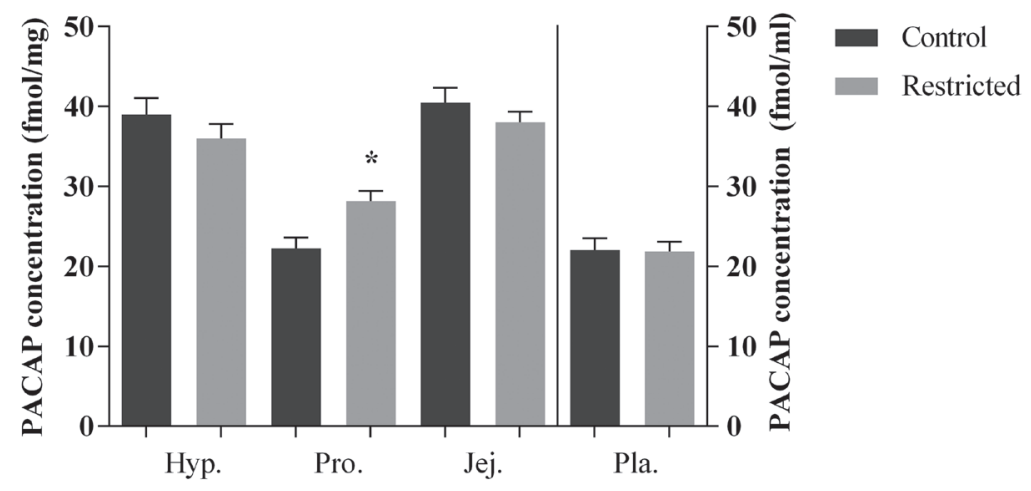

Fig. 1. PACAP-38 concentrations in tissues of ad libitum fed and feed restricted hens measured with RIA. Hyp.: hypothalamus, Pro.: proventriculus, Jej.: jejunum, Pla.: plasma. Data are represented as group means \pm SEM of 8 hens per group. $* P<0.05$

Table 2

Behavioral effect of feed restriction on hens

\begin{tabular}{|l|c|c|c|}
\hline \multirow{2}{*}{\multicolumn{1}{|c|}{ Behavioral pattern }} & \multicolumn{3}{c|}{ Average number of events $( \pm$ SEM) } \\
\cline { 2 - 4 } & Control & Restricted & $P$ \\
\hline Drinking* & $3.63 \pm 0.29$ & $1.5 \pm 0.09 *$ & 0.025 \\
\hline Eating & $6.25 \pm 0.4$ & $5.3 \pm 0.25$ & 0.492 \\
\hline Feathering & $0.81 \pm 0.11$ & $1.13 \pm 0.13$ & 0.532 \\
\hline Pecking floor & $3.44 \pm 0.35$ & $8 \pm 0.71$ & 0.060 \\
\hline Pecking grid & $1.94 \pm 0.3$ & $4.69 \pm 0.76$ & 0.252 \\
\hline Pecking tail feathers & $0.31 \pm 0.07$ & $0.56 \pm 0.07$ & 0.376 \\
\hline Resting & $0.31 \pm 0.06$ & $0.94 \pm 0.17$ & 0.235 \\
\hline Scratching & $1.31 \pm 0.18$ & $1.3 \pm 0.13$ & 1.000 \\
\hline Seeking with stretched neck & $3 \pm 0.26$ & $4.3 \pm 0.48$ & 0.434 \\
\hline Walking & $6.06 \pm 0.36$ & $7.44 \pm 0.74$ & 0.564 \\
\hline Wing stretching & $0.38 \pm 0.06$ & $0.13 \pm 0.03$ & 0.179 \\
\hline
\end{tabular}

${ }^{*} P<0.05$ vs. control group. 
which is 4-fold higher than in rats [14], but 15-fold lower than in humans [3] and 13-fold lower compared to ruminants [6]. Previous experiments [28] reported PACAP-38 concentrations similar to our results in chicken hypothalamus.

Hens were observed in their cage for general and stress related behavioral signs under ad libitum fed and calorie restricted conditions. The average numbers of events are summarized in Table 2. Significant difference $(P<0.05)$ was found only in drinking and a trend $(P=0.060)$ was observed in increased floor pecking activity as a result of lower quantity of available feed. Meanwhile stress and discomfort related behaviors like grid pecking and scratching remained unchanged.

\section{DISCUSSION}

To achieve stable body weight hypothalamus plays a central role in long-term regulation of appetite and energy balance and the most potent orexigenic peptide encoding genes (AGRP/NPY) expression increase during energy shortage in birds [4]. In chickens, it was found that intracerebro-ventricular injection of human PACAP-38 leads to a reduced food intake in one-day-old male layers in a dose dependent manner [39]. This seems to be a phylogenetically conserved function, since similar observation was made in PACAP-injected fish [29]. As PACAP administration influences feed intake in several species, conversely, feed restriction has been shown to influence endogenous PACAP level. Short-term fasting $(36 \mathrm{~h})$ caused increased PACAP peptide levels in the hypothalamus, brain stem, and telencephalon of the chicken, then returned to normal level when measured after $84 \mathrm{~h}$ [20]. Similarly, in rats, short-term fasting induced an increase in PACAP levels in the brainstem, telencephalon and hypothalamus in males, while only a tendency was observed in females [23]. In our experiment, a 5-day-long calory restriction did not alter either PACAP mRNA or PACAP-38 peptide levels, but increased PAC1 gene expression in the hypothalamus. Feeding state has a great effect on gastrointestinal tract motility [6]. Along with glucagon-like peptide-1 (GLP-1), PACAP is present in the avian intestine $[9,36]$ and takes part in the regulation of intestinal motility as a smooth muscle relaxant [30, 45]. This PACAP function has been confirmed as gastric motility is reduced when PACAP is injected peripherally [33]. Consequently we assume that increased PACAP level in the proventriculus causes a decreasing motility in response to lower feed intake. Many peptide hormones are released from the gastrointestinal tract to blood and reach its receptor on the hypothalamus to modulate feed intake [31]. PACAP can pass through the blood-brain barrier from plasma to reach the brain [10]. It is currently unknown which tissue and what kind of stimuli lead to the secretion of PACAP to chicken's blood. Its plasma level remained unchanged in birds exposed to calory restriction. To understand the role of PACAP-38 in chicken plasma and how it is secreted further investigations are requirested.

Galanin immunoreactive signal appears at day 4 during embryonic life in chicken gut and acts as a growth or differentiating factor and later the appearance in muscular layers indicates its regulatory role in intestinal motility [38]. Intracerebro-ventricular 
injection of galanin stimulated feeding behavior, but it did not affect water intake of layer and broiler chicks. It is therefore possible that galanin is one of the orexigenic peptides in the brain of chicks, as like in rodents and fishes [40]. When injected into the central nerves system, mammalian galanin did not induce feed intake in neonatal chickens [2], but it evoked food intake in adult chickens both selected for low and high body weight, and it also caused arcuate nucleus activation in hypothalamus [13]. However, galanin mRNA level did not change in the hypothalamus of rats fasted for $72 \mathrm{~h} \mathrm{[26].} \mathrm{In} \mathrm{our} \mathrm{experiment,} \mathrm{galanin} \mathrm{was} \mathrm{significantly} \mathrm{upregulated} \mathrm{in} \mathrm{the} \mathrm{jejunum}$ only in food restricted chickens. It was found that galanin treatment caused contraction of isolated hindgut samples (including proventriculus) but it resulted in a minimal response in foregut samples [8]. Brown hens, which had been fasted, showed no significant behavioral differences in stress related activities from their respective controls [42]. Similarly, we found no differences in these activities. Function of NMU in chicken is poorly understood, some experiments showed that brain injection of rat NMU suppressed feed intake in layer [22] and broiler [16] type chickens in a dosedependent manner and induced wing-flapping, a stress signal behavior in both types. Role of NMU in the gastrointestinal tract in chicken has not yet been investigated, but studies conducted on mammalian NMU proved that it acts as a smooth muscle contractor on chicken crop [31]. We recorded no wing flapping behavior during the calorie restriction and no significant gene expressional difference in hypothalamic $N M U$ gene expression. NMURs mediate NMU's effect, involved in smooth muscle contraction regulation in chicken [32]. Feed restriction induces higher gastrointestinal tract motility [6]. Therefore the possible role of increased $N M U$ expression in the jejunum can be explained as this peptide acts as a smooth muscle contractor, whereas it remained unclear why $P A C A P$ gene increased expression was observable. Similarly $\mathrm{PACl}$ gene expression was markedly elevated in other experimental settings, despite lack of changes in PACAP expression [27].

In conclusion, food restriction significantly altered gene expression of $P A C A P$ in the proventriculus and jejunum and PACl and NMUR1 gene expressions were upregulated in the hypothalamus. PACAP has an anorexigenic effect when injected centrally to chicks [36]. However PACAP concentration increases after $36 \mathrm{~h}$ fasting [19] and $P A C 1$ upregulation in the current study suggests an opposite effect. $N M U$, NMUR1 and GAL upregulation occurred in the jejunum. PACAP peptide concentration increased in the proventriculus, but its plasma level remained unchanged, suggesting that PACAP is not secreted from the gastrointestinal system into the circulation. Our results indicate that PACAP has an autocrine or paracrine, rather than an endocrine function in response to feed restriction since its plasma level remains unchanged. We assume a role for PACAP in the proventriculus and GAL in the jejunum since their gene expression was increased in hens exposed to feed restriction.

\section{ACKNOWLEDGEMENTS}

This work was supported by the New Széchenyi Plan of Hungary, co-financed by the European Social Fund (TÁMOP-4.2.2.D-15/1/KONV-2015-0016); the Ministry of National Development, Hungary 
(AGR-PIAC-13-1-2013-0008), the University of Debrecen, Hungary (RH/885/2013) GINOP-2.3.2-152016-00050 "PEPSYS", and the NKFI K104987, K119759, Bolyai Janos Scholarship, New National Excellence Program of the Ministry of Human Capacities. The authors are grateful to Gabriella Gulyás and to Ákos Tisza (University of Debrecen) for their help during sample processing.

\section{REFERENCES}

1. Andersen, C. L., Jensen, J. L., Ørntoft, T. F. (2004) Normalization of real-time quantitative reverse transcription-PCR data: A model-based variance estimation approach to identify genes suited for normalization, applied to bladder and colon cancer data sets. Cancer Res. 64, 5245-5250.

2. Ando, R., Bungo, T., Kawakami, S. I., Shimojo, M., Masuda, Y., Furuse, M. (2000) Intracerebroventricular injection of mammalian motilin, melanin-concentrating hormone or galanin does not stimulate food intake in neonatal chicks. Br. Poult. Sci. 41, 508-511.

3. Borzsei, R., Mark, L., Tamas, A., Bagoly, T., Bay, C., Csanaky, K., Banki, E., Kiss, P., Vaczy, A., Horvath, G., Nemeth, J., Szauer, E., Helyes, Z., Reglodi, D. (2009) Presence of pituitary adenylate cyclase activating polypeptide-38 in human plasma and milk. Eur. J. Endocrinol. 160, 561-565.

4. Boswell, T. (2005) Regulation of energy balance in birds by the neuroendocrine hypothalamus. The Journal of Poultry Science. 42, 161-181.

5. Cai, G., Mo, C., Huang, L., Li, J., Wang, Y. (2015) Characterization of the Two CART Genes (CART1 and CART2) in Chickens (Gallus gallus). PLoS One. 10, e0127107.

6. Clench, M., Mathias, J. (1995) Motility responses to fasting in the gastrointestinal-tract of 3 avian species. Condor. 97, 1041-1047.

7. Czegledi, L., Tamas, A., Borzsei, R., Bagoly, T., Kiss, P., Horvath, G., Brubel, R., Nemeth, J., Szalontai, B., Szabadfi, K. (2011) Presence of pituitary adenylate cyclase-activating polypeptide (PACAP) in the plasma and milk of ruminant animals. Gen. Comp. Endocrinol. 172, 115-119.

8. DeGolier, T. F., Nordell, J. N., Pust, M. H., Duke, G. E. (1999) Effect of galanin on isolated strips of smooth muscle from the gastrointestinal tract of chickens. J. Exp. Zool. 283, 463-468.

9. Ding, B., Lenzi, C., Pirone, A. (2014) Immunohistochemical study on glucagon-like peptide-1 (GLP1) and pituitary adenylate cyclase activating peptide (PACAP) in the small intestine of muscovy duck during the prehatching and posthatching periods. J. Poult. Sci. 51, 35-41.

10. Dogrukol-Ak, D., Tore, F., Tuncel, N. (2004) Passage of VIP/PACAP/secretin family across the blood-brain barrier: therapeutic effects. Curr. Pharm. Des. 10, 1325-1340.

11. Domin, J., Benito-Orfila, M. A., Nandha, K. A., Aitken, A., Bloom, S. R. (1992) The purification and sequence analysis of an avian neuromedin U. Regul. Pept. 41, 1-8.

12. Furuse, M., Matsumoto, M., Mori, R., Sugahara, K., Kano, K., Hasegawa, S. (1997) Influence of fasting and neuropeptide $\mathrm{Y}$ on the suppressive food intake induced by intracerebroventricular injection of glucagon-like peptide-1 in the neonatal chick. Brain Res. 764, 289-292.

13. Hagen, C. J., Newmyer, B. A., Webster, R. I., Gilbert, E. R., Siegel, P. B., Tachibana, T., Cline, M. A. (2013) Stimulation of food intake after central galanin is associated with arcuate nucleus activation and does not differ between genetically selected low and high body weight lines of chickens. Neuropeptides 47, 281-285.

14. Helyes, Z., Pozsgai, G., Börzsei, R., Németh, J., Bagoly, T., Márk, L., Pintér, E., Tóth, G., Elekes, K., Szolcsányi, J. (2007) Inhibitory effect of PACAP-38 on acute neurogenic and non-neurogenic inflammatory processes in the rat. Peptides 28, 1847-1855.

15. Hiramatsu, K., Yamasaki, A. (2009) Immunohistochemical study on the innervation of the chicken pancreas by pituitary adenylate cyclase-activating polypeptides (PACAPs)-containing nerves. $J$. Poult. Sci. 46, 234-239.

16. Honda, K., Saneyasu, T., Okuda, M., Uemura, T., Kamisoyama, H. (2015) Glucagon and neuromedin U suppress food intake in broiler chicks. J. Poult. Sci. 53, 268-273.

17. Howard, A. D., Wang, R. P., Pong, S. S. (2000) Identification of receptors for neuromedin U and its role in feeding. Nature 406, 70-74. 
18. Jakab, B., Reglődi, D., Józsa, R., Hollósy, T., Tamás, A., Lubics, A., Lengvári, I., Oroszi, G., Szilvássy, Z., Szolcsányi, J., Németh, J. (2004) Distribution of PACAP-38 in the central nervous system of various species determined by a novel radioimmunoassay. J. Biochem. Biophys. Methods 61, 189-198.

19. Jozsa, R., Nemeth, J., Tamas, A., Hollosy, T., Lubics, A., Peter, S., Olah, A., Lengvari, I. Reglodi, D (2005) Short-term fasting differentially affects PACAP and VIP levels in rats and chicken. Regul. Pept. 130, 166.

20. Jozsa, R., Nemeth, J., Tamas, A., Hollosy, T., Lubics, A., Jakab, B., Olah, A., Lengvari, I., Arimura, A., Reglödi, D. (2006) Short-term fasting differentially alters PACAP and VIP levels in the brains of rat and chicken. Ann. N. Y. Acad. Sci. 1070, 354-358.

21. Juhasz, T., Helgadottir, S. L., Tamas, A., Reglodi, D., Zakany, R. (2015) PACAP and VIP signaling in chondrogenesis and osteogenesis. Peptides 66, 51-57.

22. Kamisoyama, H., Honda, K., Saneyasu, T., Sugahara, K., Hasegawa, S. (2007) Central administration of neuromedin U suppresses food intake in chicks. Neurosci. Lett. 420, 1-5.

23. Kiss, P., Reglődi, D., Tamás, A., Lubics, A., Lengvári, I., Józsa, R., Somogyvári-Vigh, A., Szilvássy, Z., Németh, J. (2007) Changes of PACAP levels in the brain show gender differences following shortterm water and food deprivation. Gen. Comp. Endocrinol. 152, 225-230.

24. Klein, S., Jurkevich, A., Grossmann, R. (2006) Sexually dimorphic immunoreactivity of galanin and colocalization with arginine vasotocin in the chicken brain (Gallus gallus domesticus). J. Comp. Neurol. 499, 828-839.

25. Kuenzel, W. J., Masson, M. (1988) A stereotaxic atlas of the brain of the chick (Gallus domesticus), The John Hopkins University Press, Baltimore, MD.

26. Kumano, S., Matsumoto, H., Takatsu, Y., Noguchi, J., Kitada, C., Ohtaki, T. (2003) Changes in hypothalamic expression levels of galanin-like peptide in rat and mouse models support that it is a leptintarget peptide. Endocrinology 144, 2634-2643.

27. Lam, S., Liu, Y., Liong, E., Tipoe, G., Fung, M. L. (2012) Upregulation of pituitary adenylate cyclase activating polypeptide and its receptor expression in the rat carotid body in chronic and intermittent hypoxia. Adv. Exp. Med. Biol. 758, 301-306.

28. Luts, A., Uddman, R., Sundler, F. (1989) Neuronal galanin is widely distributed in the chicken respiratory tract and coexists with multiple neuropeptides. Cell Tissue Res. 256, 95-103.

29. Matsuda, K., Maruyama, K., Nakamachi, T., Miura, T., Shioda, S. (2006) Effects of pituitary adenylate cyclase-activating polypeptide and vasoactive intestinal polypeptide on food intake and locomotor activity in the goldfish, Carassius auratus. Ann. N. Y. Acad. Sci. 1070, 417-421.

30. Monir, M., Hiramatsu, K., Yamasaki, A., Nishimura, K., Watanabe, T. (2014) The influence of restricted feeding on glucagon-like peptide-1 (GLP-1)-containing cells in the chicken small intestine. Anat. Histol. Embryol. 43, 153-158.

31. Oclon, E., Pietras, M. (2011) Peripheral ghrelin inhibits feed intake through hypothalamo-pituitaryadrenal axis-dependent mechanism in chicken. J. Anim. Feed Sci. 20, 118-130.

32. Okimura, K., Sakura, N., Kurosawa, K., Hashimoto, T. (1992) Contractile activity of porcine neuromedin U-25 and various neuromedin U-related peptide fragments on isolated chicken crop smooth muscle. Chem. Pharm. Bull. 40, 1500-1503.

33. Ozawa, M., Aono, M., Moriga, M. (1999) Central effects of pituitary adenylate cyclase activating polypeptide (PACAP) on gastric motility and emptying in rats. Dig. Dis. Sci. 44, 735-743.

34. Peeters, K., Gerets, H. H., Princen, K., Vandesande, F. (1999) Molecular cloning and expression of a chicken pituitary adenylate cyclase-activating polypeptide receptor. Mol. Brain Res. 71, 244-255.

35. Peeters, K., Gerets, H. H., Arckens, L., Vandesande, F. (2000) Distribution of pituitary adenylate cyclase-activating polypeptide and pituitary adenylate cyclase-activating polypeptide type I receptor mRNA in the chicken brain. J. Comp. Neurol. 423, 66-82.

36. Pirone, A., Baoan, D., Piano, I., Della Santina, L., Baglini, A., Lenzi, C. (2011) Pituitary adenylate cyclase-activating peptide (PACAP) immunoreactivity distribution in the small intestine of the adult New Hampshire chicken. Acta Histochem. 113, 477-483. 
37. Racz, B., Horvath, G., Reglodi, D., Gasz, B., Kiss, P., Gallyas, F., Sumegi, B., Toth, G., Nemeth, A., Lubics, A. (2010) PACAP ameliorates oxidative stress in the chicken inner ear: an in vitro study. Regul. Pept. 160, 91-98.

38. Salvi, E., Vaccaro, R., Renda, T. G. (1999) Ontogeny of galanin-immunoreactive elements in the intrinsic nervous system of the chicken gut. Anat. Rec. 254, 28-38.

39. Tachibana, T., Saito, S., Tomonaga, S., Takagi, T., Saito, E., Boswell, T., Furuse, M. (2003) Intracerebroventricular injection of vasoactive intestinal peptide and pituitary adenylate cyclaseactivating polypeptide inhibits feeding in chicks. Neurosci. Lett. 339, 203-206.

40. Tachibana, T., Mori, M., Khan, M. S. I., Ueda, H., Sugahara, K., Hiramatsu, K. (2008) Central administration of galanin stimulates feeding behavior in chicks. Comp. Biochem. Physiol., Part A Mol. Integr. Physiol. 151, 637-640.

41. Takeuchi, S., Teshigawara, K., Takahashi, S. (2000) Widespread expression of Agouti-related protein (AGRP) in the chicken: a possible involvement of AGRP in regulating peripheral melanocortin systems in the chicken. Biochim. Biophys. Acta-Mol. Cell Res. 1496, 261-269.

42. Webster, A. B. (1995) Immediate and subsequent effects of a short fast on the behavior of laying hens. Appl. Anim. Behav. Sci. 45, 255-266.

43. Yamamoto, I., Nakao, N., Kaiya, H., Miyazato, M., Tsushima, N., Arai, T., Tanaka, M. (2011) Two chicken neuromedin $U$ receptors: Characterization of primary structure, biological activity and tissue distribution. Gen. Comp. Endocrinol. 174, 116-123.

44. Yasuhara, T., Mizuno, K., Somogyvari-Vigh, A., Komaki, G., Arimura, A. (1992) Isolation and primary structure of chicken PACAP. Regul. Pept. 37, 326.

45. Yoshida, M., Aizawa, H., Takahashi, N., Shigyo, M., Hara, N. (2000) Pituitary adenylate cyclase activating peptide mediates inhibitory nonadrenergic noncholinergic relaxation. Eur. J. Pharmacol. $395,77-83$

46. Zentel, H., Nohr, D., Muller, S., Yanaihara, N., Weihe, E. (1990) Differential occurrence and distribution of galanin in adrenal nerve-fibers and medullary cells in rodent and avian species. Neurosci. Lett. 120, 167-170. 